\title{
The physical activity paradox: a longitudinal study of the implications for burnout
}

\author{
Juriena D. de $\operatorname{Vries}^{1}$ (1) $\cdot$ Arnold B. Bakker ${ }^{1}$ (i)
}

Received: 14 July 2021 / Accepted: 9 September 2021 / Published online: 6 October 2021

(c) The Author(s) 2021

\begin{abstract}
Purpose This study investigates the independent and interactive associations of physical job demands and three types of off-job physical activity (during transportation, household, and recreation) with burnout. We use a recently proposed new conceptualization and assessment of burnout including core and secondary burnout symptoms. We predicted that physical job demands would be positively and the three types of off-job physical activity would be negatively related to burnout. Further, we hypothesized that the negative relations between the three types of off-job physical activity and burnout would be stronger for employees with low (vs. high) physical job demands.

Methods To test our hypotheses, we conducted a two-wave survey study among a heterogeneous sample of full-time workers $(N=355)$, using a longitudinal design with a half-year time lag. We tested cross-sectional, prospective and longitudinal relations.

Results Hierarchical regression analyses partly confirmed our predictions. Cross-sectionally and prospectively, it was shown that physical job demands were positively related to burnout symptoms. In addition, off-job physical activity was negatively related to primary and secondary burnout symptoms among employees with low physical job demands and positively related to burnout symptoms among employees with high physical job demands. However, these relationships disappeared when investigated longitudinally.

Conclusion Together, these findings suggest that not all off-job physical activities can prevent burnout, and that potential positive effects of physical activity during off-job time may depend on employees' physical activity level at work.
\end{abstract}

Keywords Burnout $\cdot$ Occupational stress $\cdot$ Work $\cdot$ Exercise $\cdot$ Physical job demands

Burnout, a work-related phenomenon characterized by a severe loss of physical and mental energy (Leiter et al. 2014; Schaufeli et al. 2020), is prevalent and widespread (Eurofound 2018) - it can be found among many different occupational groups. Burnout may negatively affect employees and employers, in the form of employee depression (Toker and Biron 2012) and absenteeism (Ybesma et al. 2010). Early on, burnout was conceptualized as a syndrome of exhaustion, cynicism, and reduced professional efficacy (Maslach and Leiter 2016). However, the exact conceptualization and assessment of burnout is subject to debate (Bianchi

Juriena D. de Vries

j.d.devries@essb.eur.nl

1 Center of Excellence for Positive Organizational Psychology, Erasmus University Rotterdam, Woudestein Campus, Mandeville Building T16.17, PO Box 1738, 3000 DR Rotterdam, The Netherlands et al. 2019; Kristensen et al. 2005; Schaufeli et al. 2009). Researchers recently proposed that burnout can best be conceptualized as the inability and unwillingness to spend effort at work. Accordingly, it is suggested that its core components are exhaustion, mental distancing, and cognitive and emotional impairment (Schaufeli et al. 2020).

In the present study, we sought to investigate predictors of burnout, using this new conceptualization and assessment of the syndrome. Poor working conditions, such as the combination of high job demands and low job resources, is a fertile ground for burnout (Bakker and Demerouti 2017). However, burnout may also arise if employees fail to use adaptive regulation strategies, such as recovery and job crafting, when dealing with their job demands (Bakker and de Vries 2021). Accordingly, it is essential to determine which regulation strategies may help employees deal with their ongoing job demands and prevent burnout. 
We suggest that off-job physical activity may serve as such an individual self-regulation strategy. This idea is in line with research showing that physical activity has the potential to prevent and reduce burnout (Gerber et al. 2020; Naczenski et al. 2017; Ochentel et al. 2018). However, physical activity may not play the same role for all employees. When jobs are mainly characterized by physical job demands, employees will be physically active at work throughout the whole day and across the entire workweek. Increasing evidence indicates that physical activity at work impairs physical health, whereas off-job physical activity promotes it (i.e., the 'physical activity paradox'; Coenen et al. 2020; Holtermann et al. 2018). These contrasting physical activity effects may apply to burnout as well, but, to date, these relations are not fully clear. Therefore, this study aims to investigate the relation between different domainspecific physical activities and burnout, which may help to understand how to use physical activity in an optimal way to prevent burnout. To this end, we conducted a survey study using a longitudinal design with a half-year in-between two waves of measurement. Full-time working employees answered questions about their physical activities on and off the job as well as experiences of burnout, which allows us to test temporal precedence (Spector 2019).

We aim to contribute to the literature in three ways. First, we aim to enhance insight into different domain-specific physical activities in relation to burnout. We focus on employees' physical job demands as an indicator of physical activity at work. These job demands refer to physical aspects of the job that require sustained physical effort, which cost considerable energy and bear the risk of being unhealthy (Demerouti et al. 2001; Holtermann et al. 2018). Further, we focus on different off-job physical activity types (recreational, transportation, and household physical activity) in relation to burnout. We argue that-in general (i.e., for the average worker)—physical job demands are positively and off-job physical activities are negatively related to burnout. The reason for this is that physical job demands may require sustained physical effort without sufficient recovery time and therefore overtax employees' energy reservoir (Holtermann et al. 2018; Sato et al. 2017; Xanthopoulou et al. 2007). In contrast, off-job physical activities may help gain resources that can be used to recover from and cope with job demands (Naczenski et al. 2017).

Second, we provide insight into the interplay between employees' physical demands during work and off-job physical activity. We suggest that off-job physical activity will be particularly effective in preventing burnout for employees who face low (vs. high) physical job demands (Hobfoll et al. 2018; Meijman and Mulder 1998). We argue that whereas those with low physical job demands need physical activity to compensate for their physical inactivity during the work day, those with high physical job demands cannot use the same functional system for work and recovery (Hobfoll et al. 2018; Meijman and Mulder 1998).

Third, we explore the relations between these various physical activities and burnout using a new conceptualization of burnout that supposedly aligns better with individuals' daily experience of burnout. Specifically, we use a recently developed definition and associated assessment tool-the Burnout Assessment Tool (BAT; Schaufeli et al. 2020) and contribute to the burnout literature by expanding the BAT's nomological network.

\section{Theoretical background}

\section{Burnout}

Traditionally, burnout is defined as a psychological syndrome unfolding as a prolonged response to chronic stressors on the job, consisting of exhaustion, a cynical attitude toward work, and a sense of professional inefficacy (Maslach and Leiter 2016). Over the past decades, this definition has received some criticism. For instance, Schaufeli and Taris (2005) showed that unwillingness (manifested as 'cynicism'; Taris et al. 2005), and inability (manifested as 'exhaustion') are the two core burnout symptoms (see also, Demerouti et al. 2010). These authors proposed that professional inefficacy develops largely independently of exhaustion and cynicism and is most likely a consequence of these core symptoms. Further, Schaufeli and his colleagues (2020) have argued that the original burnout definition is incomplete. They reasoned that an inability to exert effort also involves emotional and cognitive impairments (inability to control emotions, inability to concentrate and focus), and such impairments are not considered in the most common definitions of burnout. Interestingly, the authors also consider secondary symptoms that are often reported by individuals who experience burnout, including depressed mood, psychological distress, and psychosomatic complaints. Since the Maslach Burnout Inventory (Maslach et al. 1997) cannot be used to identify burnout as an overall syndrome in clinical practice (Eurofound 2018), Schaufeli et al. (2020) proposed the burnout assessment tool for diagnosing burnout. They defined burnout as employees' work-related state characterized by extreme tiredness, reduced ability to regulate cognitive and emotional processes, and mental distancing. Additionally, they included secondary burnout symptoms in this new definition (i.e., depressed mood and nonspecific psychological and psychosomatic distress symptoms) that often co-occur with the core burnout symptoms. 


\section{Physical demands in relation to burnout}

It is well known that high job demands pose an important risk of developing burnout (Alarcon 2011; Aronsson et al. 2017; Guthier et al. 2020). Job demands refer to those physical, psychological, social, or organizational aspects of the job that require sustained physical and/or psychological (cognitive and emotional) effort or skills (Demerouti et al. 2001). Therefore, job demands are associated with the activation of employees' psychophysiological systems and result in physiological and psychological costs (Demerouti and Bakker 2011). When employees are highly and constantly exposed to job demands, their psychophysiological systems remain activated, physiological and psychological costs accumulate, and adverse effects, such as burnout, may arise (Bayes et al. 2021; Oerlemans and Bakker 2014).

In the present study, we suggest that physical job demands predict burnout. Physical job demands refer specifically to physical aspects of occupational tasks, such as heavy lifting, static and constrained working postures, and other (monotonous) physical activities required to perform work tasks. There is accumulating evidence that physical job demands have adverse physical and mental health effects (e.g., Coenen et al. 2020; Holtermann et al. 2018; Li et al. 2013). One crucial problem is that consistently high physical job demands may breach employees' psychophysiological boundaries, which-over time-may lead to physical and mental health impairments. That is, physical job demands often involve occupational physical activity that is of low intensity and long duration combined with limited autonomy over how much and when to rest. Further, employees have little to say about the fit between their physical capacity and their physical demands (Holtermann et al. 2018). These demands are, by definition, hard to deal with and failure to meet the demands is likely (Schaufeli and Taris 2014). As a result, negative emotions, such as frustration, annoyance, and tension, may arise. These negative emotions need to be regulated (Gyurak et al. 2011) and may evoke feelings of emotional exhaustion and a tendency to mentally and physically withdraw from work (Boksem and Tops 2008). Moreover, it is conceivable that physical exhaustion has a reinforcing impact on mental exhaustion, as both experiences are hard to separate phenomenologically (Hockey 2013).

Little is known about the effects of physical job demands on mental health outcomes such as burnout (Cillekens et al. 2020). A possible reason is that it has been widely assumed that exposure to cognitive or emotional demands leads to burnout (Maslach and Leiter 2016). However, we argue that physical demands may also pose a risk. Research has shown that employees facing high physical job demands (i.e., blue-collar workers) can experience burnout symptoms too (Toppinen-Tannen et al. 2002). Furthermore, the few available studies show a positive relation between physical job demands and burnout (De Jonge et al. 2000; Schaufeli and Bakker 2004; Xanthopoulou et al. 2007). Given these previous empirical findings and based on the rationale that physical job demands overtax employees' energy reservoir, we propose:

Hypothesis 1: physical job demands are positively related to burnout.

\section{Physical activity as a resource-building activity}

Whereas frequent exposure to high physical job demands may be taxing, we contend that off-job physical activity (i.e., during transportation, household chores and gardening, and recreation) may generate energetic, physical, and cognitive resources that help to prevent burnout. Compared to physical job demands, off-job physical activity is often of higher intensity and shorter duration, and individuals may match their physical activity to their physical capability (Holtermann et al. 2018). This opportunity to regulate makes it more likely that the activity builds resources instead of draining them. Off-job physical activity may help to replenish resources that have been used during the workday, ensuring that employees feel re-energized when facing a new workday (i.e., 'recovery'; Sonnentag, 2003) and preventing the accumulation of physiological and psychological costs (Bayes et al. 2021). Further, off-job physical activity may help gain new additional personal resources that enable coping with future job demands (Demerouti et al. 2009; Steed et al. 2019; Ten Brummelhuis and Bakker 2012).

Off-job physical activity may build resources in various ways. First of all, off-job physical activity may improve employees' physical resources (Caspersen et al. 1985; Chatterjee et al. 2019; Schmied et al. 2020), which is important to experience job demands as not overly fatiguing or stressful. Research shows that off-job physical activity elicits the neurophysiological stress system in a way that is similar to what psychosocial stressors do. When combined with sufficient bodily recovery, physical activity may cause physiological stress adaptation, resulting in faster physiological recovery after being exposed to stress (Klaperski et al. 2014; Landers and Arent 2007; Sothmann 2006). Furthermore, offjob physical activity may help to build cognitive resources, such as executive functions and memory (Fernandes et al. 2017; Zhu et al. 2017). This may help employees to restore cognitive resources that have been lost during the workday or be more resistant to unfavorable effects of cognitive job demands (Kulikowski 2020). Third, physical activity may also facilitate psychological detachment (not thinking about work outside work hours; Demerouti et al. 2009) because attention is drawn to bodily processes (Van Hooff et al. 2019). In this way, physical activity helps employees to take a cognitive respite from work stress (Radstaak et al. 2011) 
and aids recovery (Demerouti et al. 2009). Fourth, off-job physical activity may increase momentary and lasting positive affective states, such as happiness and relaxation (e.g., Basso and Suzuki 2017; Wiese et al. 2017), and decrease momentary and lasting negative affective states, such as stress and depression (e.g., Basso and Suzuki 2017; Dishman et al. 2021). Fifth, off-job physical activity may help to build social resources. Engaging in physical activity with others may provide social support and help build a stronger social network. Social support, in turn, may facilitate adaptive coping with stressful (work) situations and hence prevent burnout (Halbesleben 2006; Rueger et al. 2016). Finally, off-job physical activity is associated with mastery experiences and personal control over the environment, resulting in increased self-efficacy (Kandola et al. 2019). Self-efficacious employees are generally better able to cope with work tasks and job stressors.

Some off-job physical activities may be more strongly related to recovery and reduced burnout than other activities. All off-job physical activity types may help to distract from work-related thoughts and increase physical and cognitive resources. However, some off-job physical activity types have a more compulsory character (household physical activities, transportation) than others (recreational activities). Furthermore, some activities are chosen for enjoyment or perceived benefits (e.g., recreational activities and gardening). Research has shown that leisure activities especially aid recovery if the activity is voluntary, desirable, and enjoyable (Isoard-Gautheur et al. 2019; Oerlemans and Bakker 2014). Recreational physical activities may be best for recovery, as these often comprise challenging activities carried out together with significant others and provide excellent opportunities for mastery experiences and social support (Deci and Ryan 2000; Van den Broeck et al. 2008). Previous research has indeed shown that off-job physical activity is negatively related to burnout (Gerber et al. 2020; Naczenski et al. 2017). However, this research did not differentiate between different types of physical activity during non-work time. We explore such differential effects in the present study and propose that all types of physical activity during non-work time can alleviate job stress and burnout.

Hypothesis 2: off-job physical activity (during transportation, household chores and gardening, and recreation) is negatively related to burnout.

\section{The combination of physical activities on and off the job}

Although physical activity is hypothesized to have a favorable impact on burnout, we expect that this effect will not be the same for employees in all possible working conditions. Specifically, we argue that physical activity during non-work hours will be more helpful to reduce or prevent burnout complaints for employees with low versus high physical job demands. Our proposition is in line with the theoretical notion that recovery from job demands particularly occurs when the resources that are needed during work are no longer called upon during leisure time and that resources are notably regained when drawing on other resources than during work (Hobfoll et al. 2018; Meijman and Mulder 1998). Although off-job physical activity may build emotional, physical, and cognitive resources, it also causes short-term depletion of physical resources (e.g., muscle tissue damage, hormonal disturbances) (GraafRoelfsema et al. 2007). This means that when employees are physically active during work and leisure time on a daily basis, they constantly appeal to their physical resources, and daily recovery may be incomplete. After a day with high physical job demands and off-job physical activity, employees start the next day in a suboptimal condition. Therefore, they need to invest compensatory effort to cope with their physical job demands, resulting in an accumulation of physiological and psychological costs. In contrast, employees who are exposed to low physical job demands only use their physical resources to a limited extent during work time. These employees will benefit more from off-job physical activity because they can build new psychological and physical resources by drawing on other resources during non-work time than during work (cf. Hobfoll et al. 2018; Meijman and Mulder 1998).

Results of empirical studies investigating the impact of the combination of physical activity on and off the job on employee health are mixed. Some studies have shown that the presence of physical activities on and off the job increases the risk of impaired mental (Asztalos et al. 2009; Cerin et al. 2009) or physical health (Clays et al. 2013; Ferrario et al. 2018). Some studies show that both physical activities do not interact and work independently (Holtermann et al. 2021; Krause et al. 2017). Other studies have shown that off-job physical activity protects blue-collar workers' physical health (Leino-Arjas et al. 2004; Quinn et al. 2021) or particularly white-collars' level of burnout (Bernaards et al. 2006; Prince et al. 2021). To the best of our knowledge, no previous study has investigated the impact of the combination of physical activity on and off the job on burnout. However, studies in the sports domain show that endurance training combined with insufficient (bodily) rest periods - a situation that resembles high physical job demands combined with high off-job physical activity-is positively related to burnout (Gustafsson 2007). Since employees with high physical job demands will not optimally use off-job physical activity to restore and build resources, whereas employees with low physical job demands can restore and build resources during non-work time through physical activity, we predict: 
Hypothesis 3: the negative relationship between off-job physical activity and burnout is moderated by physical job demands. Specifically, this relationship is stronger for employees with low (vs. high) physical job demands.

\section{Method}

\section{Procedure and participants}

This study used a two-wave full panel design with a halfyear time lag. The participants were recruited via the Website Amazon's Mechanical Turk (MTurk; www.MTurk.com). Participants filled out two surveys (T1 \& T2) in exchange for a monetary reward of $\$ 1$ each. They were eligible to participate if they were currently employed and worked full-time ( $\geq 36 \mathrm{~h}$ a week). Only participants who filled out both surveys were included in the current study. A total of $n=848$ only filled out the survey at T1, and $n=355$ filled out the questionnaire at both $\mathrm{T} 1$ and $\mathrm{T} 2$. The final sample consisted of $N=355$ participants. Of this final sample, most participants were male $(n=206,58 \%)$ and relatively young ( $40.0 \%$ between 25 and 34 years old; $29.3 \%$ between 35 and 44 years old; $15.5 \%$ between 45 and 54 years old; $<7 \%$ in other categories). All participants were U.S. residents and were employed at the time of our measurements. Furthermore, most participants were highly educated (73\% obtained at least a Bachelor's degree). Participants had relatively high levels of autonomy $(M=3.23[S D=0.63]$ on a 4-point scale $)$ and task demands ( $M=2.93[S D=0.48]$ on a 4-point scale) at work. Lastly, participants evaluated their physical fitness as above average ( $M=3.29[S D=0.77]$ on a 5-point scale).

\section{Dropout analysis}

Participants who filled out both measurements reported less secondary burnout symptoms (psychosomatic and psychological complaints; $M=2.35, S D=0.05, F(1,831)=5.80$, $\left.p=0.02, \eta^{2}=0.007\right)$ at baseline than participants who only filled out the first measurement $(M=2.50, S D=0.04)$, but did not differ on other baseline outcomes.

\section{Materials}

Off-job physical activity. Three types of off-job physical activity were measured: (a) transportation (traveling by public transport, bicycling, and walking from place to place); (b) household (vigorous and moderate housework, gardening, yard work, general maintenance work, and caring for family); and (c) recreational (vigorous and moderate physical activity for recreation, sport, exercise or leisure, and walking) using 18 items of the long version of the 'International Physical Activity Questionnaire' (IPAQ) by Hagströmer and colleagues (2006). Participants were asked about their engagement in physical activity during the last 7 days by indicating how many days and the average duration per day they engaged in a specific type of physical activity. An example item is "Think about only those physical activities that you did for at least $10 \mathrm{~min}$ at a time. During the last seven days, on how many days did you do vigorous physical activities like heavy lifting, chopping wood, shoveling snow, or digging in the garden or yard?" Participants could answer by indicating the number of days a week. After this item, the following question was asked: "How much time did you usually spend on one of those days doing vigorous physical activities in the garden or yard?" Participants could indicate the average hours/minutes per day they engage in this activity. In the current investigation, the weekly MET minutes of physical activity was used as an outcome variable. One MET is a multiple of the estimated resting energy expenditure (Forde 2018). MET minutes were calculated by multiplying the MET value given for an activity (walking $=3.3$ METs, moderate activity $=4.0 \mathrm{METs}$, and vigorous activity $=8.0$ METs) by the minutes the activity was carried out and the number of days that the activity was undertaken. We followed the IPAQ scoring protocol recommendations for data cleaning and processing (Patterson 2005). Previous research indicates that the IPAQ has acceptable measurement properties with a reliability of 0.80 (Hallal and Victora 2004) and a re-test reliability of 0.70 (Craig et al. 2003). As the IPAQ scores had skewed distributions, we log-transformed these scores before statistical analysis.

Burnout. The general version of the Burnout Assessment Tool (BAT) by Schaufeli et al. (2020) was utilized to assess the presence of core (i.e., exhaustion, mental distance, cognitive impairment, and emotional impairment) and secondary (i.e., psychological and psychosomatic complaints) burnout symptoms with 32 items that could be scored on a five-point Likert scale ranging from never (1) to always (5). Example items are 'I feel mentally exhausted' and 'I feel unable to control my emotions'. Two average scores (for core and secondary burnout symptoms) were used as outcome variables. Previous research shows that the General version of the BAT has a test-retest reliability of 0.74 (Schaufeli et al. 2020). Internal reliability of core burnout symptoms (T1: $\alpha=0.87$; T2: $\alpha=0.87$ ) and secondary burnout symptoms (T1: $\alpha=0.92$; T2: $\alpha=0.92)$ was high in the present study.

Physical demands. Physical demands were assessed with five items of the Job Content Questionnaire (Karasek et al. 1998). Items could be answered on a 4-point Likert scale, ranging from 1 (almost never) to 4 (almost always). An example item is: 'Does your work require rapid continuous physical activity?' and 'Are you required to move or lift very heavy loads in your job?' Internal reliability was good (T1: $\alpha=0.89$; T2: $\alpha=0.89$ ). 
Control variables. Age, gender and educational level were included as control variables, as these variables has been shown to be related to burnout (Brewer and Shapard 2004; Hakanen et al. 2011; Purvanonva and Muros 2010).

\section{Statistical approach}

Hierarchical regression analyses were carried out to test our hypotheses. For Hypotheses 1 and 2, two models were computed, separately for primary and secondary burnout symptoms. The first model included the control variables (age, gender, educational level). The second model included the control variables and predictor variables of interest (respectively, physical job demands [H1] and the three types of off-job physical activity [H2]). Further, three models were computed to test Hypothesis 3. The first model contained the control variables, the second model the control and predictor variables (physical job demands and the three types of off-job physical activity), and in the third model the three interaction terms were added (between physical job demands and each off-job physical activity type). When a significant interaction term was found, the Johnson-Neyman technique was used to interpret the interaction (Carden et al. 2017). The Johnson-Neyman technique allows for identifying the regions in the range of the moderator variable where the effect of the predictor on the outcome is statistically significant.

\section{Results}

\section{Descriptive statistics}

Table 1 displays the means $(M)$, standard deviations $(S D)$, and correlations $(r)$ of all outcome variables. As can be seen in Table 1, burnout remained very stable between $\mathrm{T} 1$ and $\mathrm{T} 2$, as indicated by a correlation of 0.81 for core and 0.74 for secondary symptoms. As these large auto-correlations do not leave much variance to be explained, we report prospective results (X at T1 Y at T2) in this results section. The results of cross-sectional analyses (X-Y relations tested at one time point, $\mathrm{T} 1$ or $\mathrm{T} 2$ ) and longitudinal analyses ( $\mathrm{X}$ at $\mathrm{T} 1 \mathrm{Y}$ at $\mathrm{T} 2$, controlled for $\mathrm{Y}$ at T1) can be found in the Supplementary Material.

\section{Physical job demands predicting burnout}

See Table 2 for the results of testing Hypothesis 1 (physical job demands are positively related to burnout). The first model shows that the control variables accounted for a significant amount of variance in core and secondary burnout symptoms. Age turned out to be a significant predictor of core $(\beta=-0.38)$ and secondary $(\beta=-0.33)$

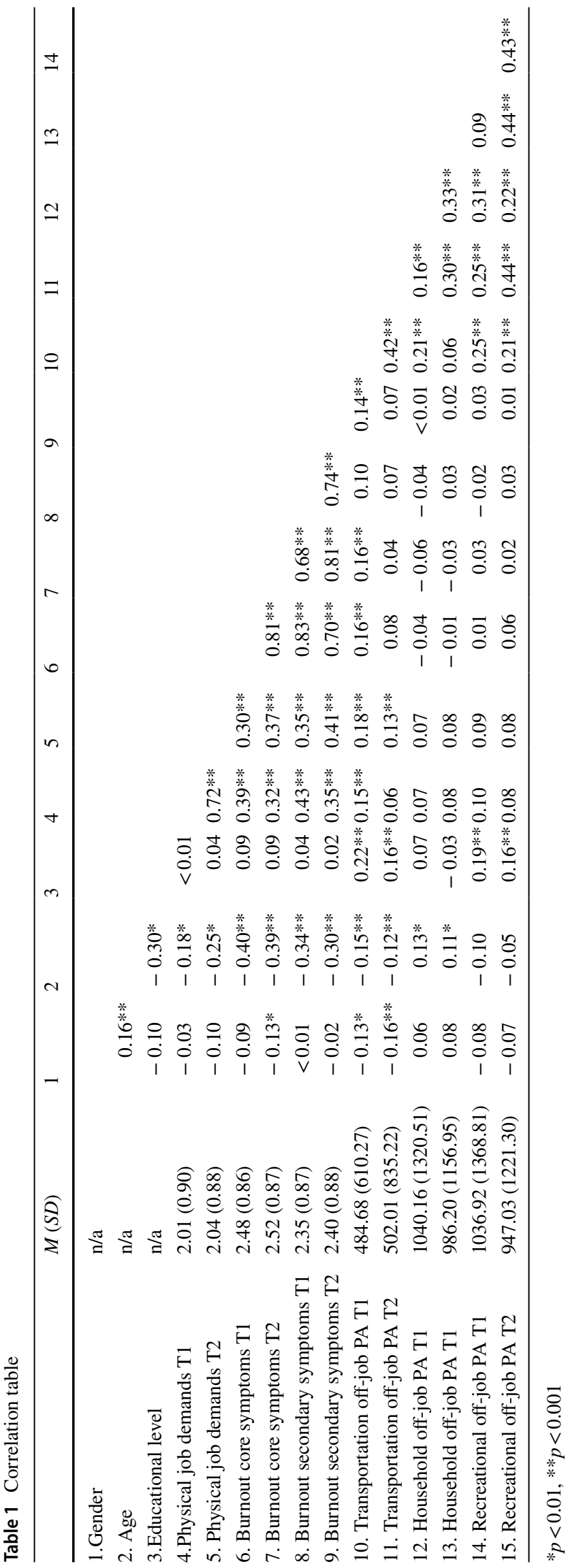


Table 2 Prospective regression models predicting core and secondary burnout symptoms at T2 from physical job demands at T1

\begin{tabular}{|c|c|c|c|c|c|c|c|c|c|c|c|c|}
\hline & \multicolumn{6}{|c|}{ Core burnout symptoms (T2) } & \multicolumn{6}{|c|}{ Secondary burnout symptoms (T2) } \\
\hline & \multicolumn{3}{|l|}{ Model 1} & \multicolumn{3}{|l|}{ Model 2} & \multicolumn{3}{|c|}{ Model 1} & \multicolumn{3}{|l|}{ Model 2} \\
\hline & $b$ & $S E$ & $p$ & $b$ & $S E$ & $P$ & $\bar{b}$ & SE & $p$ & $\bar{b}$ & SE & $p$ \\
\hline Constant & 3.71 & 0.30 & $<0.001$ & 3.04 & 0.31 & $<0.001$ & 3.37 & 0.31 & $<0.001$ & 2.57 & 0.32 & $<0.001$ \\
\hline Gender & -0.13 & 0.09 & 0.13 & -0.13 & 0.08 & 0.13 & 0.05 & 0.09 & 0.58 & 0.06 & 0.09 & 0.52 \\
\hline Age & -0.30 & 0.04 & $<0.001$ & -0.26 & 0.04 & $<0.001$ & -0.26 & 0.04 & $<0.001$ & -0.22 & 0.04 & $<0.001$ \\
\hline Educational level & -0.05 & 0.08 & 0.51 & -0.03 & 0.08 & 0.68 & -0.11 & 0.08 & 0.18 & -0.09 & 0.08 & 0.28 \\
\hline Physical job demands T1 & & & & & 0.25 & $<0.001$ & & & & 0.30 & 0.05 & $<0.001$ \\
\hline$F$ & 21.38 & & & 24.44 & & & 12.63 & & & 20.24 & & \\
\hline$R^{2}$ & 0.15 & & & 0.22 & & & 0.10 & & & 0.19 & & \\
\hline Adjusted $R^{2}$ & 0.15 & & & 0.21 & & & 0.09 & & & 0.18 & & \\
\hline$\Delta R^{2}$ & & & & 0.06 & & & 0.10 & & & 0.09 & & \\
\hline
\end{tabular}

burnout symptoms-older employees were less likely to experience these symptoms. Gender and educational level were not related to core and secondary burnout symptoms. In the second model, physical job demands were entered into the regression models, which showed a significant improvement of the models for both core and secondary symptoms. Results revealed that physical job demands were positively related to core $(\beta=0.26)$ and secondary $(\beta=0.31)$ burnout symptoms. This means that Hypothesis 1 is supported prospectively. The positive associations were also found cross-sectionally (at $\mathrm{T} 1$ or at T2). However, the positive associations disappeared when controlling for previous levels of the outcome variables (see Supplementary Material).

\section{Off-job physical activities predicting burnout}

See Table 3 for the results to test Hypothesis 2 (the three types of off-job physical activity [transportation, household, and recreation physical activity] are negatively related to burnout). In the first step, control variables were included. The second model, including the addition of the three types of off-job physical activity, showed no significant improvement of the first model for both core and secondary burnout symptoms (see $\Delta \mathrm{R}^{2}$ in Table 3). Contrary to expectations, in the second model, transportation physical activity was positively related to core $(\beta=0.11)$ and secondary $(\beta=0.12)$ burnout symptoms. Household and recreation physical activity were not related to core (respectively $\beta=-0.03$ and $\beta=-0.02$ ) and secondary (respectively $\beta=0.03$ and $\beta=-0.02$ ) burnout symptoms. This means that Hypothesis 2 is not supported. The positive association between

Table 3 Prospective regression models predicting core and secondary burnout symptoms at T2 from the different types of off-job physical activity at $\mathrm{T} 1$

\begin{tabular}{|c|c|c|c|c|c|c|c|c|c|c|c|c|}
\hline & \multicolumn{6}{|c|}{ Core burnout symptoms (T2) } & \multicolumn{6}{|c|}{ Secondary burnout symptoms (T2) } \\
\hline & \multicolumn{3}{|l|}{ Model 1} & \multicolumn{3}{|l|}{ Model 2} & \multicolumn{3}{|c|}{ Model 1} & \multicolumn{3}{|l|}{ Model 2} \\
\hline & $b$ & $S E$ & $p$ & $b$ & $S E$ & $P$ & $b$ & SE & $p$ & $b$ & SE & $p$ \\
\hline Constant & 3.71 & 0.30 & $<0.001$ & 3.63 & 0.31 & $<0.001$ & 3.37 & 0.31 & $<0.001$ & 3.22 & 0.32 & $<0.001$ \\
\hline Gender & -0.13 & 0.09 & 0.13 & -0.11 & 0.09 & 0.13 & 0.05 & 0.09 & 0.58 & 0.07 & 0.09 & 0.45 \\
\hline Age & -0.30 & 0.04 & $<0.001$ & -0.29 & 0.04 & $<0.001$ & -0.26 & 0.04 & $<0.001$ & -0.26 & 0.04 & $<0.001$ \\
\hline Educational level & -0.05 & 0.08 & 0.51 & -0.08 & 0.08 & 0.35 & -0.11 & 0.08 & 0.18 & -0.15 & 0.08 & 0.08 \\
\hline Transportation physical activity $\mathrm{T} 1$ & & & & 0.04 & 0.02 & 0.03 & & & & 0.04 & 0.02 & 0.03 \\
\hline Household physical activity T1 & & & & -0.01 & 0.02 & 0.60 & & & & 0.01 & 0.02 & 0.64 \\
\hline Recreation physical activity $\mathrm{T} 1$ & & & & -0.01 & 0.02 & 0.74 & & & & -0.01 & 0.02 & 0.75 \\
\hline$F$ & 21.38 & & & 11.51 & & & 12.63 & & & 7.34 & & \\
\hline$R^{2}$ & 0.15 & & & 0.17 & & & 0.10 & & & 0.11 & & \\
\hline Adjusted $R^{2}$ & 0.15 & & & 0.15 & & & 0.09 & & & 0.10 & & \\
\hline$\Delta R^{2}$ & & & & 0.01 & & & & & & 0.02 & & \\
\hline
\end{tabular}


transportation physical activity and core burnout symptoms was also found at T1 (cross-sectionally), but not at T2 (cross-sectionally) or longitudinally, and not for secondary burnout symptoms (see Supplementary Material).

\section{Interactions of off-job physical activities and physical job demands with burnout}

Results of testing Hypothesis 3 (the negative relation between off-job physical activity and burnout is stronger for employees with low vs. high physical job demands) can be found in Table 4. The second model, including the predictor variables (physical job demands and the three types of off-job physical activity), shows a significant improvement of the first model that only included control variables for both core and secondary burnout symptoms. In these second models, physical job demands significantly predicted burnout, and transportation, household, and recreational physical activity were unrelated to burnout. The third model, including the interaction terms between physical job demands and each of the three types of off-job physical activity, was significantly better than the second model for core burnout but not for secondary burnout symptoms (see $\Delta \mathrm{R}^{2}$ in Table 4). Results revealed no interaction between physical job demands and transportation and household physical activity on core and secondary burnout symptoms. However, the interactions between physical job demands and recreational physical activity significantly predicted core and secondary burnout symptoms. These significant interactions for core burnout symptoms are illustrated in Fig. 1 and for secondary burnout symptoms in Fig. 2. The Johnson-Neyman technique (Carden et al. 2017) showed that the relationship between recreational physical activity and core burnout symptoms was significant and negative when physical job demands were low (lower than $M=1.36$ on a 4-point scale), and significant and positive when physical job demands were high (higher than $M=3.15$ on a 4-point scale). Similarly, the Johnson-Neyman technique revealed that the relationship between recreational physical activity and secondary burnout symptoms was significant and negative when physical job demands were low (lower than $M=1.35$ on a 4-point scale), and significant and positive when physical job demands were high (higher than $M=2.73$ on a 4-point scale). Given that the interplay between recreational physical activity and physical job demands was significant in predicting burnout, but physical job demands did not interact with transportation and household physical activity in predicting burnout, we conclude that Hypothesis 3 is partly supported. The interaction between physical job demands and recreational physical activity was also found cross-sectionally (at $\mathrm{T} 1$ or at T2). However, the interaction disappeared when controlling for previous levels of the outcome variables. Furthermore, a significant interaction between household physical activity and physical job demands was found at $\mathrm{T} 2$, suggesting a buffering effect of household physical activity on the positive relation between physical job demands and burnout (see Supplementary Material).

\section{Discussion}

This study aimed to investigate different domain-specific physical activities (work vs. leisure time) in relation to burnout. To better align with the experience of burnout in practice, we used a recent new conceptualization and assessment of burnout (Schaufeli et al. 2020). We found that physical job demands and transportation physical activity were positively related to burnout symptoms. Household physical activity was unrelated to burnout symptoms. Further, we found that recreational physical activity was only negatively related to burnout symptoms among employees with low physical job demands. In contrast, recreational physical activity was related to more burnout symptoms among employees with high physical job demands.

\section{Theoretical implications}

The present study has several theoretical implications. First, our research contributes to the literature by showing that a distinction between different domain-specific physical activities is relevant for predicting burnout. In contrast to earlier notions that physical activity may prevent and reduce burnout (Gerber et al. 2020; Naczenski et al. 2017; Ochentel et al. 2018), we showed that specific physical activities, i.e., physical job demands and transportation physical activity, were positively related to burnout symptoms. The positive association between physical job demands and burnout is in line with the 'physical activity health paradox' stating that physical activity at work impairs health, whereas off-job physical activity promotes it (Coenen et al. 2020; Holtermann et al. 2018). It is important to note that previous research on this paradox mainly focused on the adverse effects of physical activity at work on physical health (Cillekens et al. 2020). We showed that these adverse effects may also apply to burnout. The finding that transportation physical activity was positively related, and household physical activity was unrelated to burnout were contrary to our expectations and the 'physical activity health paradox' (Coenen et al. 2020; Holtermann et al. 2018). It is conceivable that the beneficial effects of the different types of off-job physical activity are only visible under certain circumstances. For instance, transportation physical activity could be a source of stress when it is compulsory (Isoard-Gautheur et al. 2019) or is carried out in an environment with noise, pollution, or a poor infrastructure (Asztalos et al. 2009; Chatterjee et al. 2019). Regarding household physical activity, it is possible 


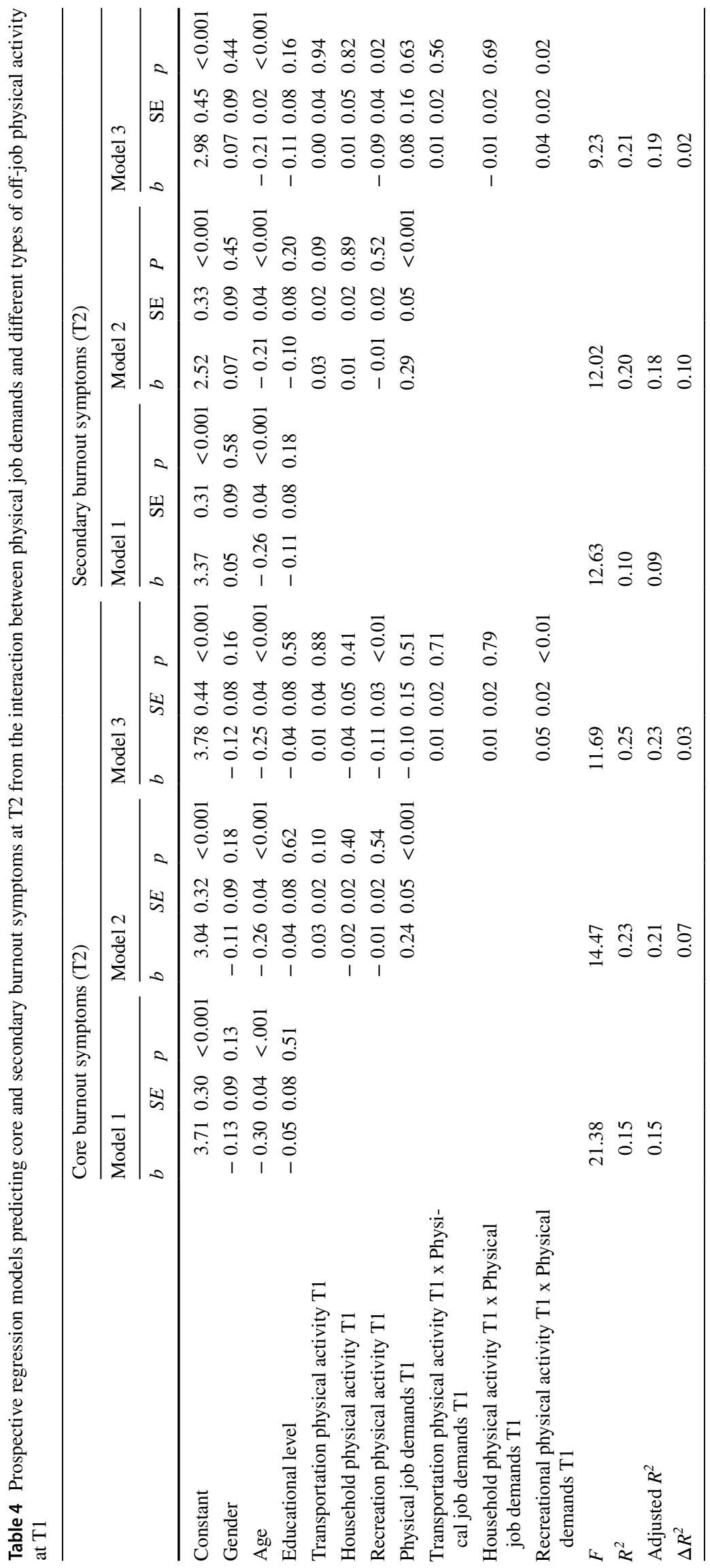


Fig. 1 Physical job demands as a moderator in the relation between recreational physical activity and core burnout symptoms
Fig. 2 Physical demands as a moderator in the relation between recreational physical activity and secondary burnout symptoms
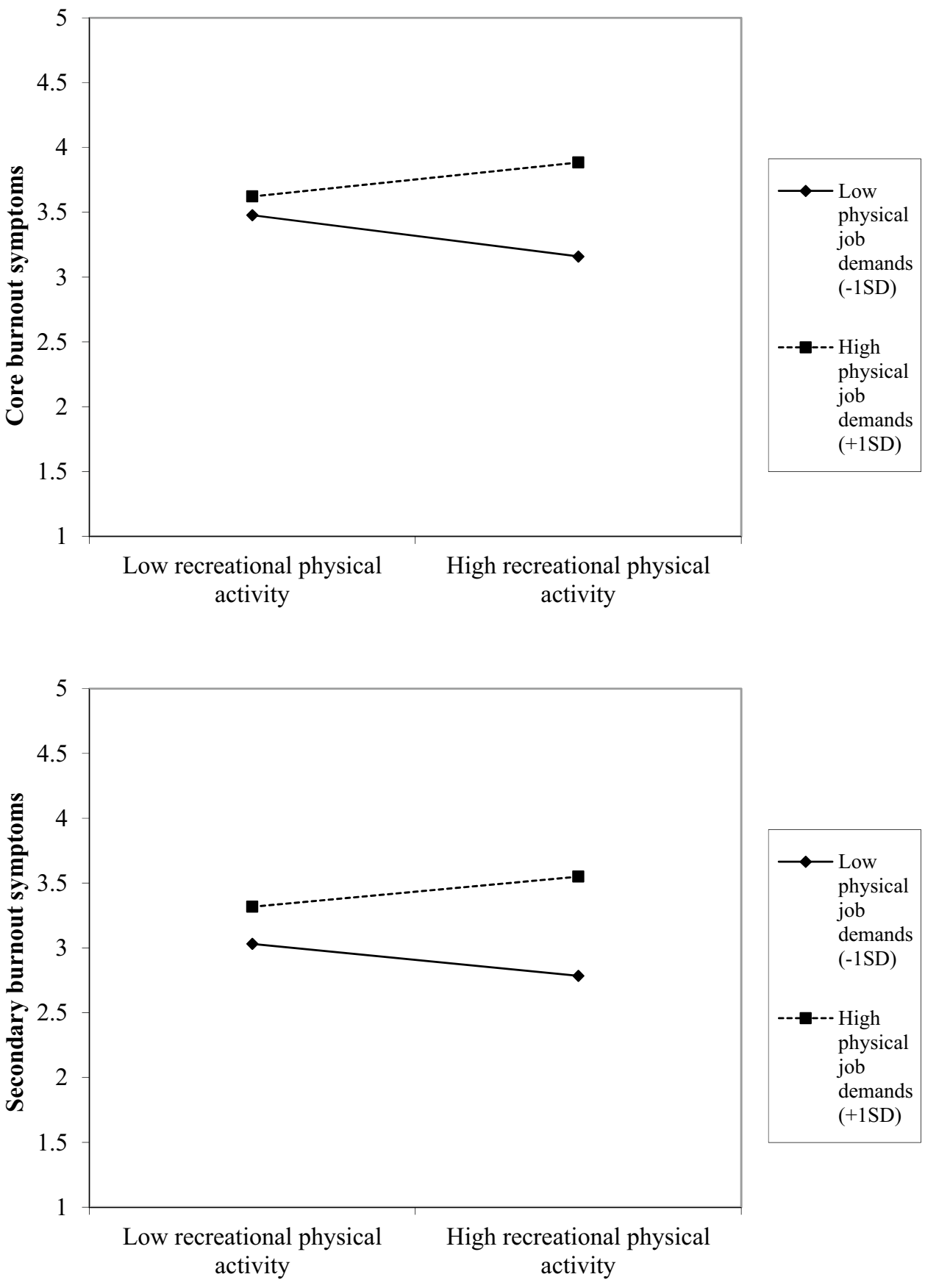

that these activities simultaneously facilitate recovery (e.g., through the distraction of work) and hamper relaxation and mastery (e.g., because of their obligatory and repetitive character), which may result in null findings.

A second contribution is that we showed that certain physical activities interact in predicting burnout. It was demonstrated that recreational physical activity was only related to fewer burnout symptoms among employees with low physical job demands. Moreover, recreational physical activity was related to more burnout symptoms among employees with high physical job demands. These findings suggest that the simultaneous enactment of different physical activities alters their potential unique effects (cf. Prince et al. 2021). Therefore, researchers should not restrict themselves to one domain-specific physical activity when studying possible positive effects following physical activity. The results are in line with theoretical notions that recovery from job demands mainly occurs when the resources that are needed during work are no longer called upon during leisure time and that resources are notably regained when drawing on other resources than during work (Hobfoll et al. 2018; Meijman and Mulder 1998). Furthermore, our findings are in line 
with the contention that physical activity causes short-term depletion of physical resources (e.g., muscle tissue damage, hormonal disturbances; Graaf-Roelfsema et al. 2007) andwhen it is not combined with sufficient bodily recoverymay result in an accumulation of physiological and psychological costs, eventually resulting in adverse outcomes such as burnout (see Demerouti et al. 2009).

Third, by showing that different physical activities and their interplay with physical job demands contribute to burnout, we expand the nomological network of a new definition of burnout (Schaufeli et al. 2020). These findings confirm previous suggestions and findings that non-work factors could be antecedents of burnout (Bianchi et al. 2021). Furthermore, the finding that the relations between the different physical activities and burnout did not differ based on whether core or secondary symptoms were included in the analyses is consistent with the notion that secondary burnout symptoms such as depressive and psychosomatic complaints are important indicators of burnout (Schaufeli et al. 2020). Further, whereas previous studies mainly showed that prolonged exposure to cognitive or emotional job demands leads to burnout (Maslach and Leiter 2016), we showed that exposure to physical job demands might lead to burnout as well. Just like cognitive and emotional job demands, physical job demands presumably contribute to sustained activation of physiological stress systems (e.g., autonomic nervous system and adrenal medullary axis; see Bayes et al. 2021), which may result in burnout (Landers and Arent 2007; Sothmann 2006).

\section{Strengths, limitations, and suggestions for future research}

This study has several strengths. We used a time-lagged design that provided opportunities for testing relations and temporal precedence (the 'cause' should occur before the 'outcome'), which are both criteria of determining causality (Spector 2019). Additionally, this study is high in ecological validity, as we used a new conceptualization and assessment of burnout that closely matches the daily burnout experience (Schaufeli et al. 2020). Finally, we incorporated various domain-specific physical activity types, which gives a more fine-grained understanding of how physical activity and burnout are related.

Despite the study's strengths, several limitations of this study need to be addressed. First, we cannot make causal claims. We found that core and secondary burnout symptoms were highly stable over a half year. This stability implies that it is statistically speaking rather challenging to detect acrosstime relations. Indeed, we found that physical activities and burnout were cross-sectionally and prospectively related, but these relations disappeared when investigated longitudinally (i.e., when we controlled for the outcome at baseline). Thus, we could not find evidence for the idea that physical activity is related to a change in burnout. Earlier studies revealed that cross-lagged effects on burnout occurred at longer time intervals (see e.g., De Vries et al. 2016; Naczenski et al. 2017; Guthier et al. 2020). Accordingly, we suggest that future research adopts a more extended time lag ( $\geq 1$ year) to study physical activity and burnout over time. Furthermore, if possible, including more than two measurement occasions is desirable to maximize the chances of finding the appropriate time lag (Guthier et al. 2020; Spector 2019).

Second-related to the previous limitation-we were not able to control for all relevant third variables, which is essential to allow for more robust causal inferences (Spector and Brannick 2011). For instance, we selected full-time working employees, but did not measure participants' actual work hours. Previous research has shown that excessive work hours and working overtime are negatively related to off-job physical activity (Kirk and Rhodes 2011) and positively to burnout (Rabenu and Aharoni-Goldenberg 2017). Work hours may thus have acted as a potential third variable. Accordingly, in future research, we suggest incorporating these variables as controls (see Spector and Brannick 2011 for suggestions on how to do this).

The third limitation concerns our physical activity measure. Physical activity was self-reported. Although this measure has been found to be reliable and valid (Craig et al. 2003; Hallal and Victora 2004), research has also shown that people sometimes find it difficult to adequately recall their actual physical activity level (Dowd et al. 2018). Furthermore, our used measure did not explicitly ask for strength training (i.e., it was asked how much time/how many days participants engaged in moderate and vigorous activities, and some examples of these activities were provided), while previous research indicates that this type of physical activity may have health benefits among employees with physically demanding work (Sundstrup et al. 2020). Preferably, future research should include device-based measures such as accelerometers or specifically ask for strength training to better assess physical activity (Skotte et al. 2014).

The fourth limitation relates to the generalizability of our findings. We studied full-time working employees (US residents) who were also enrolled in Amazon's MTurk. Although previous research concludes that MTurk samples are a viable source for occupational health research (Michel et al. 2018; Keith et al. 2017), it has been shown that MTurk samples tend to be younger, more educated, have lower income, engage in less healthy behaviors, and have more mental health problems than nationally representative samples (Keith et al. 2017; Walters et al. 2018). Further, whitecollar employees (especially employed in technological jobs) seem to be slightly overrepresented compared to blue-collar employees (Michel et al. 2018). A positive point is that MTurk samples seem to come from a more diverse set of 
industries than samples typically used in occupational health research (Michel et al. 2018; Keith et al. 2017). To increase generalizability, we suggest that future research replicate our findings using representative samples of the general population, preferably including more blue-collar workers.

Fifth, it is possible that attrition bias has played a role in this study, since participants who dropped out at the second measurement reported more secondary burnout symptoms at baseline (medium effect size). This systematic attrition might have resulted in a restriction of range in burnout and an underestimation of the found relations (Asendorpf et al. 2014). Unfortunately, attrition is very common in longitudinal studies. We suggest that future research tries to limit attrition or use multiple imputations when data are missing at random (see e.g., Asendorpf et al. 2014).

\section{Practical implications}

Our research has several practical implications. We found that full-time workers exposed to physical job demands are at higher risk for burnout. This result and the previously found adverse health effects of physically demanding work (Coenen et al. 2020; Holtermann et al. 2018) highlight the importance of organizational preventive measures such as supervisor support (Clays et al. 2016), decision authority, skill discretion (Viotti et al. 2017), workplace strength training (Sundstrup et al. 2020), and exoskeletons (Shepertycky et al. 2021) to buffer the negative effects of high physical job demands. Further, to prevent incomplete recovery from work, it seems advisable that full-time working employees with physically demanding work do not overly engage in recreational physical activities during non-work time. Possibly, these employees could benefit from other recovery strategies that do not require sustained physical effort, such as social and relaxation activities (Sonnentag et al. 2017). In contrast, for full-time working employees with low physical demands (white-collar workers), it seems advisable to engage in recreational physical activity to enhance work recovery and prevent burnout.

\section{Conclusion}

This study shows that physical activities on and off the job interact and do not play the same role in preventing burnout. Our findings point to a physical activity paradox in which physically demanding work is related to more burnout symptoms, and that recreational physical activity strengthens this relationship. In contrast, recreational physical activity is related to fewer burnout symptoms among employees who do not have physically demanding work. These findings suggest that employees' off-job physical activity should be tailored based on employees' level of physical activity at work to lower the risk of job burnout. To allow for firmer causal inferences regarding the relations between different physical activities and burnout, we suggest that future longitudinal investigations use longer time intervals between measurement points, control for relevant third variables, use devicebased physical activity measures, and try to limit systematic attrition.

Supplementary Information The online version contains supplementary material available at https://doi.org/10.1007/s00420-021-01759-y.

Author contributions $\mathrm{JV}$ and $\mathrm{AB}$ both devised the conceptual ideas and wrote the paper. JV collected the data and performed the analysis.

Funding Not applicable.

Data availability Data and material can be requested from the corresponding author.

Code availability Not applicable.

\section{Declarations}

Conflict of interest We have no known conflict of or competing interest to disclose.

Ethical approval Our research adheres to the Netherlands Code of Conduct for Research Integrity.

Consent to participate Informed consent was obtained from all individual participants included in the study.

Consent for publication Consent for publication was obtained from all individual participants included in the study.

Open Access This article is licensed under a Creative Commons Attribution 4.0 International License, which permits use, sharing, adaptation, distribution and reproduction in any medium or format, as long as you give appropriate credit to the original author(s) and the source, provide a link to the Creative Commons licence, and indicate if changes were made. The images or other third party material in this article are included in the article's Creative Commons licence, unless indicated otherwise in a credit line to the material. If material is not included in the article's Creative Commons licence and your intended use is not permitted by statutory regulation or exceeds the permitted use, you will need to obtain permission directly from the copyright holder. To view a copy of this licence, visit http://creativecommons.org/licenses/by/4.0/.

\section{References}

Alarcon GM (2011) A meta-analysis of burnout with job demands, resources, and attitudes. J Vocat Behav 79:549-562. https://doi. org/10.1016/j.jvb.2011.03.007

Aronsson G, Theorell T, Grape T, Hammarström A, Hogstedt C, Marteinsdottir I, Skoog I, Träskman-Bendz HC (2017) A systematic review including meta-analysis of work environment and burnout symptoms. BMC Public Health 17:264. https://doi.org/10.1186/ s12889-017-4153-7 
Asendorpf JB, van de Schoot R, Denissen JJA, Hutteman R (2014) Reducing bias due to systematic attrition in longitudinal studies: the benefits of multiple imputation. Int J Behav Dev 38:453-460. https://doi.org/10.1177/0165025414542713

Asztalos M, Wijndaele K, De Bourdeaudhuij I, Philippaerts R, Matton L, Duvigneaud N, Thomis M, Duquet W, Lefevre J, Cardon G (2009) Specific associations between types of physical activity and components of mental health. J Sci Med Sport 12:468-474. https://doi.org/10.1016/j.jsams.2008.06.009

Bakker AB, Demerouti E (2017) Job demands-resources theory: taking stock and looking forward. J Occup Health Psychol 22:273-285. https://doi.org/10.1037/ocp0000056

Bakker AB, de Vries JD (2021) Job Demands-Resources theory and self-regulation: new explanations and remedies for job burnout. Anxiety Stress Coping 34:1-21. https://doi.org/10.1080/10615 806.2020.1797695

Basso JC, Suzuki WA (2017) The effects of acute exercise on mood, cognition, neurophysiology, and neurochemical pathways: a review. Brain Plast 2:127-152. https://doi.org/10.3233/ BPL-160040

Bayes A, Tavella G, Parker G (2021) The biology of burnout: causes and consequences. World J Biol Psychiatry. https://doi.org/10. 1080/15622975.2021.1907713

Bernaards CM, Jans MP, Van den Heuvel SG, Hendriksen IJ, Houtman IL, Bongers PM (2006) Can strenuous leisure time physical activity prevent psychological complaints in a working population? Occup Environ Med 63:10-16. https://doi.org/10.1136/ oem.2004.017541

Bianchi R, Schonfeld IS, Laurent E (2019) Burnout: Moving beyond the status quo. Int J of Stress Manag 26:36-45. https://doi.org/ $10.1037 /$ str0000088

Bianchi R, Manzano-Garcia G, Rolland JP (2021) Is burnout primarily linked to work-situated factors? A relative weight analytic study. Front Psychol. https://doi.org/10.3389/fpsyg.2020.623912

Boksem MAS, Tops M (2008) Mental fatigue: costs and benefits. Brain Res Rev 59:125-139. https://doi.org/10.1016/j.brainresrev.2008. 07.001

Brewer EW, Shepard L (2004) Employee burnout: a meta-analysis of the relationship between age or years of experience. Hum Resour Dev Rev 3:102-123. https://doi.org/10.1177/1534484304263335

Carden SW, Holtzman NS, Strube MJ (2017) CAHOST: an excel workbook for facilitating the Johnson-Neyman Technique for two-way interactions in multiple regression. Front Psychol 8:1293. https:// doi.org/10.3389/fpsyg.2017.01293

Caspersen CJ, Powell KE, Christenson GM (1985) Physical activity, exercise, and physical fitness: definitions and distinctions for health-related research. Public Health Rep 100:126-131

Cerin E, Leslie E, Sugiyama T, Owen N (2009) Associations of multiple physical activity domains with mental well-being. Ment Health Phys Act 2:55-64. https://doi.org/10.1016/j.mhpa.2009. 09.004

Chatterjee K, Chng S, Clark B, Davis A, De Vos J, Ettema D, Handy S, Martin A, Reardon L (2019) Commuting and wellbeing: a critical overview of the literature with implications for policy and future research. Transp Rev 40:5-34. https://doi.org/10.1080/ 01441647.2019.1649317

Cillekens B, Lang M, van Mechelen W, Verhagen E, Huysmans MA, Holtermann A, van der Beek AJ, Coenen P (2020) How does occupational physical activity influence health? An umbrella review of 23 health outcomes across 158 observational studies. Br J Sports Med 54:1474-1481. https://doi.org/10.1136/bjspo rts-2020-102587

Clays E, De Bacquer D, Janssens H, De Clercq B, Casini A, Braeckman L, Kittel F, De Backer G, Holtermann A (2013) The association between leisure time physical activity and coronary heart disease among men with different physical work demands: a prospective cohort study. Eur J Epidemiol 28:241-247. https://doi.org/10. 1007/s10654-013-9764-4

Clays E, Casini A, Van Herck K, De Bacquer D, Kittel F, De Backer G, Holtermann A (2016) Do psychosocial job resources buffer the relation between physical work demands and coronary heart disease? A prospective study among men. Int Arch Occup Environ Health 89:1299-1307. https://doi.org/10.1007/ s00420-016-1165-z

Coenen P, Huysmans MA, Holtermann A, Krause N, van Mechelen W, Straker LM, van der Beek AJ (2020) Towards a better understanding of the "physical activity paradox": the need for a research agenda. Br J Sports Med 54:1055-1057. https://doi.org/ 10.1136/bjsports-2019-101343

Craig CL, Marshall AL, Sjöström M, Bauman AE, Booth ML, Ainsworth BE, Pratt M, Ekelund U, Yngve A, Sallis JF, Oja P (2003) International physical activity questionnaire: 12 -country reliability and validity. Med Sci Sports Exerc 35:1381-1395. https://doi. org/10.1249/01.MSS.0000078924.61453.FB

De Jonge J, Dollard M, Dormann C, Le Blanc PM (2000) The demandcontrol model: specific demands, specific control, and welldefined groups. Int J Stress Manag 7:269-287. https://doi.org/ 10.1023/A:1009541929536

De Vries JD, Claessens BJC, Van Hooff MLM, Geurts SAE, Van den Bossche SNJ, Kompier MAJ (2016) Disentangling longitudinal relations between physical activity, work-related fatigue, and task demands. Int Arch Occup Environ Health 89:89-101. https://doi. org/10.1007/s00420-015-1054-x

Deci EL, Ryan RM (2000) The "what" and "why" of goal pursuits: human needs and the self-determination of behavior. Psychol Inq 11:227-268. https://doi.org/10.1207/S15327965PLI1104_01

Demerouti E, Bakker AB (2011) The Job Demands-Resources model: challenges for future research. SA J Ind Psychol 37:1-9. https:// doi.org/10.4102/sajip.v37i2.974

Demerouti E, Bakker AB, Nachreiner F, Schaufeli WB (2001) The Job Demands-Resources model of burnout. J Appl Psychol 86:499512. https://doi.org/10.1037/0021-9010.86.3.499

Demerouti E, Bakker AB, Geurts SAE, Taris TW (2009) Daily recovery from work-related effort during non-work time. Curr Persp on Job Stress Recov Res Occup Stress Wellbeing 7:85-123. https:// doi.org/10.1108/S1479-3555(2009)0000007006

Demerouti E, Mostert K, Bakker AB (2010) Burnout and work engagement: a thorough investigation of the independency of both constructs. J Occup Health Psychol 15:209-222. https://doi.org/10. 1037/a0019408

Dishman RK, McDowell CP, Herring MP (2021) Customary physical activity and odds of depression: a systematic review and metaanalysis of 111 prospective cohort studies. Br J Sport Med. https://doi.org/10.1136/bjsports-2020-103140

Dowd KP, Szeklicki R, Minetto MA, Murphy MH, Polito A, Van der Ploeg H, Ekelund U, Maciaszek J, Stemplewski R, Tomczak M, Donnelly AE (2018) A systematic literature review of reviews on techniques for physical activity measurement in adults: a DEDIPAC study. Int J Behav Nutr Phys Act 15:15. https://doi.org/10. $1186 /$ s $12966-017-0636-2$

Eurofound (2018), Burnout in the workplace: A review of data and policy responses in the EU, Publications Office of the European Union, Luxembourg

Fernandes J, Arida RM, Gomez-Pinilla F (2017) Physical exercise as an epigenetic modulator of brain plasticity and cognition. Neurosci Biobehav Rev 80:443-456

Ferrario MM, Roncaioli M, Veronesi G, Holtermann A, Clays E, Borchini R, Cavicchiolo M, Grassi G, Cesane G (2018) Differing associations for sport versus occupational physical activity and cardiovascular risk. Heart 104:1165-1172. https://doi.org/10. 1136/heartjnl-2017-312594 
Forde C (2018). Scoring the International Physical Activity Questionnaire (IPAQ). https://ugc.futurelearn.com/uploads/files/bc/ c5/bcc53b14-ec1e-4d90-88e3-1568682f32ae/IPAQ_PDF.pdf Accessed July 12021

Gerber M, Schilling R, Colledge F, Ludyga S, Pühse U, Brand S (2020) More than a simple pastime? The potential of physical activity to moderate the relationship between occupational stress and burnout symptoms. Int J Stress Manag 27:53-64. https://doi.org/10. 1037/str0000129

Graaf-Roelfsema E, Keizer HA, van Breda E, Wijnberg ID, Van der Kolk JH (2007) Hormonal responses to acute exercise, training and overtraining a review with emphasis on the horse. Vet Q 29:82-101. https://doi.org/10.1080/01652176.2007.9695232

Gustafsson H (2007). Burnout in competitive and elite athletes. Dissertation, Örebro University

Guthier C, Dormann C, Voelkle MC (2020) Reciprocal effects between job stressors and burnout: a continuous time meta-analysis of longitudinal studies. Psychol Bull 146:1146-1173. https://doi. org $/ 10.1037 /$ bul0000304

Gyurak A, Gross JJ, Etkin A (2011) Explicit and implicit emotion regulation: a dual-process framework. Cogn Emot 25:400-412. https://doi.org/10.1080/02699931.2010.544160

Hagströmer M, Oja P, Sjöström M (2006) The International Physical Activity Questionnaire (IPAQ): a study of concurrent and construct validity. Public Health Nutr 9:755-762. https://doi. org/10.1079/PHN2005898

Hakanen JJ, Bakker AB, Jokisaari M (2011) A 35-year follow-up study on burnout among Finnish employees. J Occup Health Psychol 16:345-360. https://doi.org/10.1037/a0022903

Hallal PC, Victora CG (2004) Reliability and validity of the International Physical Activity Questionnaire (IPAQ). Med Sci Sports Exerc 36:556. https://doi.org/10.1249/01.mss.00001 17161.66394 .07

Halbesleben JRB (2006) Sources of social support and burnout: a meta-analytic test of the conservation of resources model. J Appl Psychol 91:1134-1145. https://doi.org/10.1037/00219010.91.5.1134

Hobfoll SE, Halbesleben J, Neveu J-P, Westman M (2018) Conservation of resources in the organizational context: the reality of resources and their consequences. Annu Rev Organ Psychol Organ Behav 5:103-128. https://doi.org/10.1146/annurevorgpsych-032117-104640

Hockey R (2013) The psychology of fatigue: work, effort and control. Cambridge University Press. https://doi.org/10.1017/CBO97 81139015394

Holtermann A, Krause N, Van der Beek AJ, Straker L (2018) The physical activity paradox: six reasons why occupational physical activity (OPA) does not confer the cardiovascular health benefits that leisure time physical activity does. Br J Sports Med 52:149-150

Holtermann A, Schnohr P, Nordestgaard BG, Marott JL (2021) The physical activity paradox in cardiovascular disease and allcause mortality: the contemporary Copenhagen General Population Study with 104046 adults. Eur Heart J 42:1499-1511. https://doi.org/10.1093/eurheartj/ehab087

Isoard-Gautheur S, Ginoux C, Gerber G, Sarrazin P (2019) The stress-burnout relationship: examining the moderating effect of physical activity and intrinsic motivation for off-job physical activity. Workplace Health Saf 67:350-360. https://doi.org/10. 1177/2165079919829497

Kandola A, Ashdown-Franks G, Hendrikse J, Sabiston CM, Stubbs B (2019) Physical activity and depression: towards understanding the antidepressant mechanisms of physical activity. Neurosci Biobehav Rev 107:525-539. https://doi.org/10.1016/j.neubi orev.2019.09.040
Karasek R, Brisson C, Kawakami N, Houtman I, Bongers P, Amick B (1998) The Job Content Questionnaire (JCQ): an instrument for internationally comparative assessments of psychosocial job characteristics. J Occup Health Psychol 3:322-355. https:// doi.org/10.1037/1076-8998.3.4.322

Keith MG, Tay L, Harms PD (2017) Systems perspective of amazon mechanical turk for organizational research: review and recommendations. Front Psychol 8:1359. https://doi.org/10.3389/ fpsyg.2017.01359

Kirk MA, Rhodes RE (2011) Occupation correlates of adults' participation in leisure-time physical activity: a systematic review. Am J Prev Med 40:476-485. https://doi.org/10.1016/j.amepre. 2010.12.015

Klaperski S, Von Dawans B, Heinrichs M, Fuchs R (2014) Effects of a 12-week endurance training program on the physiological response to psychosocial stress in men: a randomized controlled trial. J Behav Med 37:1118-1133. https://doi.org/10. 1007/s10865-014-9562-9

Krause N, Arah OA, Kauhanen J (2017) Physical activity and 22-year all-cause and coronary heart disease mortality. Am J Ind Med 60:976-990. https://doi.org/10.1002/ajim.22756

Kristensen TS, Borritz M, Villadsen E, Christensen KB (2005) The Copenhagen Burnout Inventory: a new tool for the assessment of burnout. Work Stress 19:192-207. https://doi.org/10.1080/ 02678370500297720

Kulikowski K (2020) Cognitive abilities-a new direction in burnout research. Eur J Work Organ Psychol. https://doi.org/10.1080/ 1359432X.2020.1841284

Landers DM, Arent SM (2007) Physical activity and mental health. In: Tenenbaum G, Eklund RC (eds) Handbook of sport psychology. John Wiley \& Sons, Inc., pp 469-491

Leino-Arjas P, Solovieva S, Riihimäki H, Korjonen J, Telama R (2004) Leisure time physical activity and strenuousness of work as predictors of physical functioning: a 28 year follow up of a cohort of industrial employees. Occup Environ Med 61:1032-1038. https://doi.org/10.1136/oem.2003.012054

Leiter MP, Bakker AB, Maslach C (2014) Burnout at work: a psychological perspective. Psychology Press. https://doi.org/10. 4324/978131589416

Li J, Loerbroks A, Angerer P (2013) Physical activity and risk of cardiovascular disease. Curr Opin Cardiol 28:575-583. https://doi. org/10.1097/HCO.0b013e328364289c

Maslach C, Leiter MP (2016) Understanding the burnout experience: recent research and its implications for psychiatry. World Psychiatry 15:103-111. https://doi.org/10.1002/wps.20311

Maslach C, Jackson SE, Leiter MP (1997) Maslach Burnout Inventory: Third edition. In: Zalaquett CP, Wood RJ (eds) Evaluating stress: a book of resources. Scarecrow Education, pp 191-218

Meijman TF, Mulder G (1998) Psychological aspects of workload. In: Drenth PJD, Thierry H, de Wolff CJ (eds) Handbook of work and organizational: Work psychology. Psychology Press/ Erlbaum (UK) Taylor \& Francis, pp 5-33

Michel JS, O’Neill SK, Hartman P, Lorys A (2018) Amazon's mechanical turk as a viable source for organizational and occupational health research. Occup Health Sci 2:83-98. https:// doi.org/10.1007/s41542-017-0009-x

Naczenski LM, de Vries JD, van Hooff MLM, Kompier MAJ (2017) Systematic review of the association between physical activity and burnout. J Occup Health 59:477-494. https://doi.org/10. 1539/joh.17-0050-RA

Ochentel O, Humphrey C, Pfeifer K (2018) Efficacy of exercise therapy in persons with burnout. A systematic review and metaanalysis. J Sports Sci Med 17:475-484

Oerlemans WGM, Bakker AB (2014) Burnout and daily recovery: a day reconstruction study. J Occup Health Psychol 19:303-314. https://doi.org/10.1037/a0036904 
Patterson E (2005). Guidelines for Data Processing and Analysis of the International Physical Activity Questionnaire (IPAQ). https://www.ipaq.ki.se Accessed July 4

Prince SA, Rasmussen CL, Biswas A, Holtermann A, Aulakh T, Merucci K, Coenen P (2021) The effect of leisure time physical activity and sedentary behaviour on the health of workers with different occupational physical activity demands: a systematic review. Int J Behav Nutr Phys Act 18:100. https://doi.org/10. 1186/s12966-021-01166-z

Purvanonva RK, Muros JP (2010) Gender differences in burnout: a meta-analysis. J Vocat Behav 77:168-185. https://doi.org/10. 1016/J.JVB.2010.04.006

Quinn TD, Yorio PL, Smith PM, Seo Y, Whitfield GP, Gibbs BB (2021) Occupational physical activity and cardiovascular disease in the United States. Occup Environ Med 78:724-730. https://doi.org/10.1136/oemed-2020-106948

Rabenu E, Aharoni-Goldenberg S (2017) Understanding the relationship between overtime and burnout. Int Stud Manag Organ 47:324-335. https://doi.org/10.1080/00208825.2017.1382269

Radstaak M, Geurts SAE, Brosschot JF, Cillessen AHN, Kompier MAJ (2011) The role of affect and rumination in cardiovascular recovery from stress. Int J Psychophysio 81:237-244. https:// doi.org/10.1016/j.ijpsycho.2011.06.017

Rueger SY, Malecki CK, Pyun Y, Aycock C, Coyle S (2016) A metaanalytic review of the association between perceived social support and depression in childhood and adolescence. Psychol Bull 142:1017-1067. https://doi.org/10.1037/bul0000058

Sato TO, Hallman DM, Kristiansen J, Skotte JH, Holtermann A (2017) Different autonomic responses to occupational and leisure time physical activities among blue-collar workers. Int Arch Occup Environ Health 91:293-304. https://doi.org/10.1007/ s00420-017-1279-y

Schaufeli WB, Bakker AB (2004) Job demands, job resources, and their relationship with burnout and engagement: a multi-sample study. J Organ Behav 25:293-315. https://doi.org/10.1002/job.248

Schaufeli WB, Taris TW (2005) The conceptualization and measurement of burnout: common ground and worlds apart. Work Stress 19:256-262. https://doi.org/10.1080/02678370500385913

Schaufeli WB, Taris TW (2014) A critical review of the job demandsresources model: implications for improving work and health. Bridging occupational, organizational and public health. Springer, Dordrecht

Schaufeli WB, Desart S, De Witte H (2020) Burnout Assessment Tool (BAT) — development, validity and reliability. Int J Environ Res Public Health 17:9495. https://doi.org/10.3390/ijerph17249495

Schaufeli WB, Leiter MP, Maslach C (2009) Burnout: 35 years of research and practice. Career Dev Int 14:204-220. https://doi. org/10.1108/13620430910966406

Schmied C, Loidl M, Rossi V, Puente La, de Battre MDF, Reich B, Josef N, Niederseer D (2020) Dose-response relationship of active commuting to work: results of the GISMO study. Scand $\mathbf{J}$ Med Sci Spor 30:50-58. https://doi.org/10.1111/sms.13631

Shepertycky M, Burton S, Dickson A, Liu Y-F, Li Q (2021) Removing energy with an exoskeleton reduces the metabolic cost of walking. Sci 372:957-960. https://doi.org/10.1126/science.aba9947

Skotte J, Korshøj M, Kristiansen J, Hanisch C, Holtermann A (2014) Detection of physical activity types using triaxial accelerometers. J Phys Act Health 11(1):76-84. https://doi.org/10.1123/ jpah.2011-0347

Sonnentag S (2003) Recovery, work engagement, and proactive behavior: a new look at the interface between nonwork and work. J Appl Psychol 88:518-528. https://doi.org/10.1037/0021-9010.88.3.518

Sonnentag S, Venz L, Casper A (2017) Advances in recovery research: what have we learned? What should be done next? J Occup Health Psychol 22:365-380. https://doi.org/10.1037/ocp0000079
Sothmann MS (2006) The Cross-Stressor Adaptation Hypothesis and Exercise Training. In: Acevedo EO, Ekkekakis P (eds) Psychobiology of physical activity. Human Kinetics, pp 149-160

Spector PE (2019) Do not cross me: optimizing the use of cross-sectional designs. J Bus Psychol 34:125-137. https://doi.org/10. 1007/s10869-018-09613-8

Spector PE, Brannick MT (2011) Methodological urban legends: the misuse of statistical control variables. Organ Res Methods 14:287-305. https://doi.org/10.1177/1094428110369842

Steed LB, Swider BW, Keem S, Liu JT (2019) Leaving work at work: a meta-analysis on employee recovery from work. J Manag 47:867-897. https://doi.org/10.1177/0149206319864153

Sundstrup E, Seeberg KGV, Bengtsen E, Andersen LL (2020) A systematic review of workplace interventions to rehabilitate musculoskeletal disorders among employees with physical demanding work. J Occup Rehabil 30:588-612. https://doi.org/10.1007/ s10926-020-09879-x

Taris TW, Le Blanc PM, Schaufeli WB, Schreurs PJG (2005) Are there causal relationships between the dimensions of the Maslach Burnout Inventory? a review and two longitudinal tests. Work Stress 19:238-255. https://doi.org/10.1080/02678370500270453

Ten Brummelhuis LL, Bakker AB (2012) Staying engaged during the week: the effect of off-job activities on next day work engagement. J Occup Health 17:445-455. https://doi.org/10.1037/a0029213

Toker S, Biron M (2012) Job burnout and depression: unraveling their temporal relationship and considering the role of physical activity. J Appl Psychol 97:699-710. https://doi.org/10.1037/a0026914

Toppinen-Tannen S, Kalimo R, Mutanen P (2002) The process of burnout in white-collar and blue-collar jobs: eight-year prospective study of exhaustion. J Organ Behav 23:555-570. https://doi.org/ 10.1002/job. 155

Van den Broeck A, Vansteenkiste M, De Witte H, Lens W (2008) Explaining the relationships between job characteristics, burnout, and engagement: the role of basic psychological need satisfaction. Work Stress 22:277-294. https://doi.org/10.1080/02678 370802393672

Van Hooff MLM, Benthem de Grave RM, Geurts SAE (2019) No pain, no gain? Recovery and strenuousness of physical activity. J Occup Health Psychol 24:499-511

Viotti S, Martini M, Converso D (2017) Are there any job resources capable of moderating the effect of physical demands on work ability? A study among kindergarten teachers. Int J Occup Saf Ergon 23:544-552. https://doi.org/10.1080/10803548.2016. 1267976

Walters K, Christakis DA, Wright DR (2018) Are Mechanical Turk worker samples representative of health status and health behaviors in the U.S.? PLoS ONE 13:e0198835. https://doi.org/10. 1371/journal.pone.0198835

Wiese CW, Kuykendall L, Tay L (2017) Get active? A meta-analysis of leisure-time physical activity and subjective well-being. J Posit Psychol 13:57-66. https://doi.org/10.1080/17439760.2017.1374436

Xanthopoulou D, Bakker AN, Dollard M, Demerouti E, Schaufeli WB, Taris TW, Schreurs PJG (2007) When do job demands particularly predict burnout?: the moderating role of job resources. J Manag Psychol 22:766-786. https://doi.org/10.1108/02683940710837714

Ybesma JF, Smulders PGW, Bongers PM (2010) Antecedents and consequences of employee absenteeism: a longitudinal perspective on the role of job satisfaction and burnout. Eur J Work Organ Psychol 19:102-124. https://doi.org/10.1080/13594320902793691

Zhu W, Wadley VG, Howard VJ, Hutto B, Blair SN, Hooker SP (2017) Objectively measured physical activity and cognitive function in older adults. Med Sci Sports Exerc 49:47-53

Publisher's Note Springer Nature remains neutral with regard to jurisdictional claims in published maps and institutional affiliations. 